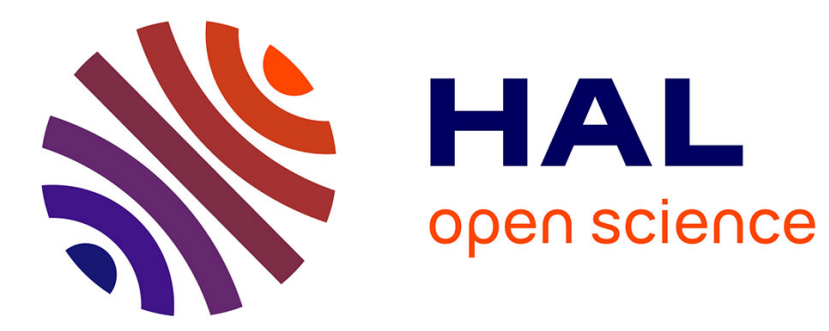

\title{
Synthesis, Characterization, and Reaction of Divinyl-substituted Laddersiloxanes
}

Yujia Liu, Aimi Endo, Peiyao Zhang, Akira Takizawa, Nobuhiro Takeda, Armelle Ouali, Masafumi Unno

\section{- To cite this version:}

Yujia Liu, Aimi Endo, Peiyao Zhang, Akira Takizawa, Nobuhiro Takeda, et al.. Synthesis, Characterization, and Reaction of Divinyl-substituted Laddersiloxanes. Silicon, 2021, 10.1007/s12633-02101068-6 . hal-03425730

\section{HAL Id: hal-03425730 \\ https://hal.science/hal-03425730}

Submitted on 11 Nov 2021

HAL is a multi-disciplinary open access archive for the deposit and dissemination of scientific research documents, whether they are published or not. The documents may come from teaching and research institutions in France or abroad, or from public or private research centers.
L'archive ouverte pluridisciplinaire HAL, est destinée au dépôt et à la diffusion de documents scientifiques de niveau recherche, publiés ou non, émanant des établissements d'enseignement et de recherche français ou étrangers, des laboratoires publics ou privés. 


\title{
Synthesis, Characterization, and Reaction of Divinyl-substituted Laddersiloxanes
}

\author{
Yujia Liu, ${ }^{1,2}$ Aimi Endo, ${ }^{2}$ Peiyao Zhang, ${ }^{3}$ Akira Takizawa, ${ }^{2}$ Nobuhiro Takeda, ${ }^{2}$ Armelle \\ Ouali, ${ }^{* 1,3}$ Masafumi Unno*1,2 \\ 1 Gunma University Initiative for Advanced Research (GIAR)-International Open Laboratory with Institute Charles \\ Gerhardt Montpellier ICGM, Univ. Montpellier, CNRS, ENSCM, France. Gunma University, Kiryu 376-8515, Japan \\ 2 Department of Chemistry and Chemical Biology, Graduate School of Science and Technology. Gunma University, \\ Kiryu 376-8515, Japan \\ 3 ICGM, Univ. Montpellier, CNRS, ENSCM, 8 rue de l'Ecole Normale, 34296 Montpellier Cedex 05, France \\ ORCID numbers. Yujia Liu: 0000-0002-3610-6355, Nobuhiro Takeda: 0000-0001-5732-758X, Armelle Ouali: 0000- \\ 0001-7436-776X, Masafumi Unno: 0000-0003-2158-1644 \\ e-mail. Armelle Ouali: armelle.ouali@enscm.fr, Masafumi Unno: unno@gunma-u.ac.jp
}

\section{Abstract}

\section{Purpose}

Silsesquioxanes with well-defined structures have been of great interest recently because of their superior properties. Among them, laddersiloxanes (ladder-type silsesquioxanes with defined structure) are less explored because step-by-step synthesis is usually necessary. In order to investigate the properties of laddersiloxanes, and apply these compounds as monomer precursors to high function materials, we prepared laddersiloxanes with reactive vinyl groups.

\section{Method}

The target compounds were obtained in a two-step reaction from commercially available alkoxysilanes, and total yields were $73-93 \%$. Three product stereoisomers were fully investigated by spectroscopic methods and structures were determined.

\section{Results}

As an extension of our previous research on constructing new laddersiloxanes, we will describe here the synthesis, characterization, and functionalization of novel divinylsubstituted laddersiloxanes. Further transformation of all products proceeded smoothly, and extended laddersiloxanes were obtained by hydrosilylation. One isomer was isolated and the structure was determined unequivocally by X-ray analysis. 


\section{Conclusion}

The laddersiloxanes described here have two reactive vinyl groups at each end of the molecule. Various reactions including hydrosilylation, polymerization, or olefin metathesis are possible, thus these compounds can be potential monomers for highly functionalized materials.

\section{Keywords silsesquioxane • well-defined structure • hydrosilylation • laddersiloxane • crystal structure}

\section{Introduction}

Inorganic-organic hybrid materials find increasing application in various fields. For their construction, polyhedral oligomeric silsesquioxanes (POSSs) are recognized as highly attractive building blocks. Indeed, with an inorganic Si-O-Si nanocore and surrounding reactive organic groups, they permit hybridization at the molecular level [1-5]. Moreover, their multifunctionality, high processability and easy functionalization constitute major assets as well.

Cage silsesquioxanes have therefore been used as key starting blocks to design hybrid materials presenting a great potential in various fields including catalysis, photoactive materials, sensing, liquid crystals, energy-related materials, medicine, self-healing materials, biomass-based nanocomposites or coating materials [6-12]. To date, the cubic SQs have been the most widely used to reach hybrid polymers with various topologies (telechelic, starshaped, side chain, cross-linked networks and so on) [8]. Generally, the incorporation of SQs in polymer hybrids or polymer composite results in an enhancement of thermal stability, mechanical (strength, hardness) and dielectric properties [1-12].

Recently, the development of difunctionalized double-decker silsesquioxanes (DDSQ), another class of silsesquioxane compounds involving $\mathrm{Si}-\mathrm{O}-\mathrm{Si}$ bonds different from the symmetrical cubic $\mathrm{T}_{8}-\mathrm{SQs}$, opened new opportunities to design hybrid materials [13]. For example, difuctionalized $\mathrm{D}_{2} \mathrm{~T}_{8}$ DDSQ has been successfully incorporated into the backbone 
chain of polymers and they conferred excellent transparency and flexibility, good solubility in addition to good thermal, mechanical and dielectric properties [14].

For more extensive investigation of hybrid materials with unexpected properties, the design and synthesis of other topologically structured silsesquioxanes, like ladder-type silsesquioxanes (laddersiloxanes), are strongly required. Laddersiloxanes possessing highly ordered double-chain structures and possibly presenting polymeric forms are of particular interest in several fields such as optics $[15,16]$ or electronics $[17,18]$. The preparation of tricyclic, pentacyclic [19-22], heptacyclic [23], and nonacyclic [24] SQs was previously reported and these well-defined compounds displayed a high thermal stability [25]. Moreover, the ladder structure was shown to give the highest refractive index and Abbe number among linear, cyclic, or cage silsesquioxanes [26]. Nevertheless, examples of hybrid materials derived from molecular laddersiloxanes are rare [27]. To open new prospects in this field, the discovery of functionalizable versions of well-defined molecular laddersiloxanes appears as a favorable research endeavor. Along these lines, we recently reported the preparation of tricyclic ladder silsesquioxanes with 6-8-6 fused rings bearing four reactive vinyl or allyl substituents on the D-group silicon atoms. The latter could be transformed easily into the corresponding tetrachloro- [28] or tetramercapto- [29] laddersiloxanes through hydrosilylation or thiol-ene reactions, respectively. Some of us also reported the functionalization of phenyl-substituted 8-8-8-laddersiloxanes through Friedel-Crafts acylation to prepare nanoporous materials for water-treatment, which shows the potential of hybrid materials based on laddersiloxanes [27].

In this report, the preparation and characterization of four ladder-shaped silsesquioxanes bearing two peripheral reactive vinyl groups are described. With phenyl or isobutyl substituents present on the core, the molecules were obtained as mixtures of stereoisomers. The successful functionalization of both external vinyl substituents via hydrosilylation was also demonstrated in the case of the most thermally stable laddersiloxane. Lastly, one isomer was isolated after functionalization and was fully characterized. The difunctionalized laddersiloxanes reported here constitute attractive building blocks to prepare hybrid materials. 


\section{Methods}

The targeted difunctionalized laddersiloxanes were prepared from all-cis-tetraphenylcyclotetrasiloxanetetraol $\left(\mathrm{T}_{4}-\mathrm{Ph}-\mathrm{OH}, \mathbf{1 a}\right)$ and all-cis-tetraisobutyl-cyclotetrasiloxanetetraol ( $\left.\mathrm{T}_{4}-i-\mathrm{Bu}-\mathrm{OH}, \mathbf{1 b}\right)$ (Scheme 1). Both of these precursors were obtained in high yields (80 and $74 \%$, respectively) from phenyltrimethoxysilane and isobutyltrimethoxysilane respectively according to previously reported procedures [26,30,31].
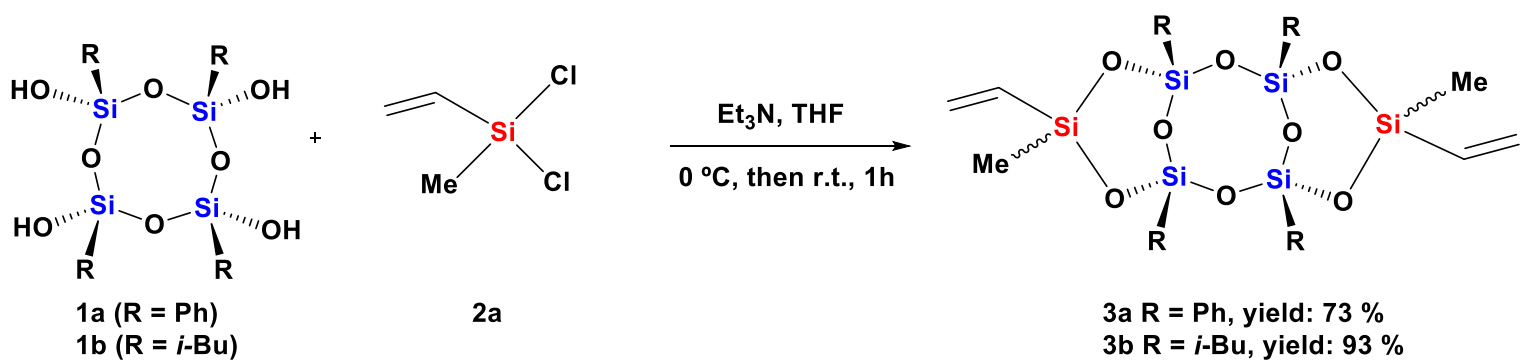

3a $\mathrm{R}=\mathrm{Ph}$, yield: $73 \%$ 3b R = i-Bu, yield: $93 \%$

Scheme 1 Synthesis of laddersiloxanes $\mathbf{3 a}$ and $\mathbf{3 b}$

\section{Results}

A solution of dichloromethylsilane $\mathbf{2 a}$ in anhydrous THF was added dropwise to a mixture of tetrasilanol 1a or $\mathbf{1 b}$ and distilled triethylamine (used as an $\mathrm{HCl}$ scavenger) in anhydrous THF to afford expected laddersiloxanes $\mathbf{3 a}$ and $\mathbf{3 b}$ in 73 and 93\% yields, respectively. In both cases, $\mathbf{3 a}$ and $\mathbf{3 b}$ were obtained after a straightforward work-up as mixtures of stereoisomers that were characterized by various analytical techniques including elemental analyses, multinuclear NMR and mass spectroscopy. The structures of three possible syn-type isomers are presented in Scheme 2. In isomers (I) and (III), the substituents of the D-group silicon atoms $\left(\mathrm{R}^{1}\right)$ are magnetically equivalent. In the same manner, the groups $\mathrm{R}^{2}$ borne by $\mathrm{T}$-group silicon atoms also have the same chemical environment and will thus give the same NMR signal. In constrast, in isomer (II), both substituents $\mathrm{R}^{1}$ present on the peripheral D-group silicon atoms are expected to give rise to two distinct sets of signals. Likewise, two different magnetic environments can be observed for the $\mathrm{R}^{2}$ groups of isomer (II) which are thus expected to show two different NMR patterns. 


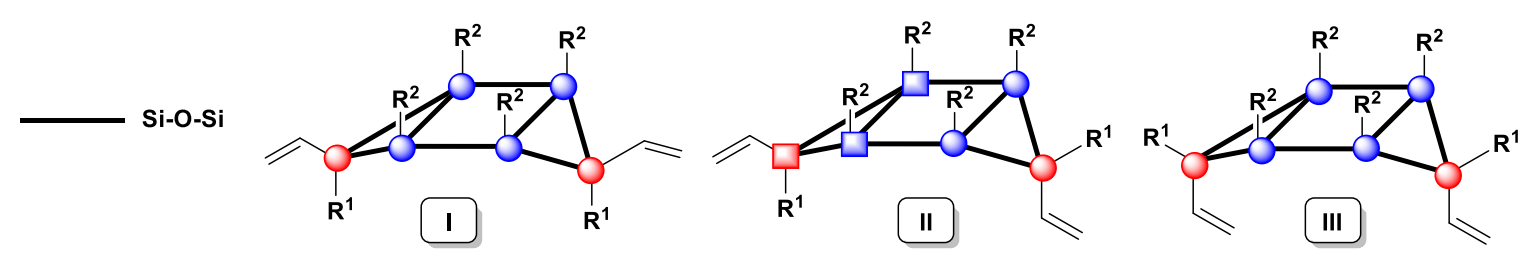

Scheme 2 Possible syn-type isomers for prepared laddersiloxanes

The ${ }^{1} \mathrm{H}$ NMR spectrum of 3a clearly illustrated the presence of several isomers with methyl groups $\left(\mathrm{R}^{1}=\mathrm{Me}\right)$ showing four distinct singlets at $0.42,0.43,0.49$, and $0.55 \mathrm{ppm}$, respectively (Figure 1, a): one would correspond to the methyl groups of isomer (I), another one to isomer (III), the last two peaks corresponding to nonequivalent methyl substituents borne by D-group silicon atoms of isomer II (Scheme 2, $\mathrm{R}^{1}$ ). Each of these signals having roughly the same intensity, the isomer ratio (I/I//III) was estimated to be approximatively $(1: 2: 1)$ in the case of $\mathbf{3 a}$ (Figure 1, a). Accordingly, for $\mathbf{3 b}$, four resonances were observed for the methyl groups at $0.26,0.27,0.28$, and $0.32 \mathrm{ppm}$ (Figure 1, b). The determination of the isomer ratio (I/II/III) was hampered by overlapping signals. Along the same lines, the vinyl groups of isomers give rise to a complex pattern in the $6.06-6.25 \mathrm{ppm}$ range for 3a (Figure 1, a) and between 5.89 and 6.08 ppm for $\mathbf{3 b}$ (Figure 1, b).

By ${ }^{29} \mathrm{Si}$ NMR (Figure 2), the appearance of patterns could be observed for T-group silicon atoms (between -67.85 and -67.77 ppm for 3a (Figure 2, a) and between -55.66 and -55.51 ppm for $\mathbf{3 b}$ (Figure 1, b). The more shielded resonances at ca. $-55 \mathrm{ppm}$ in the case of $\mathbf{3 b}$ (compared to ca. $-67 \mathrm{ppm}$ for 3a) can be rationalized by the positive inductive effect of the more donating isobutyl substituents (compared to the phenyl groups) on the $\mathrm{T}_{4}$-unit. D-group silicon atoms resonated as four singlets at $-19.23,-19.09,-18.65$, and $-18.54 \mathrm{ppm}$ for $\mathbf{3 a}$ (Figure 2, a) and $-21.03,-20.89,-20.56$, and -20.51 ppm for $\mathbf{3 b}$ (Figure 2, b). Elemental analysis and MALDI-TOF mass spectroscopy spectra were in accordance with the molecular structures (see supporting information). Attempts to separate the stereoisomers by crystallization, column chromatography on silica gel or recycle-type reverse-phase HPLC failed at this stage. Nevertheless, the laddersiloxanes may be further used as isomers mixtures for the preparation of hybrid materials 


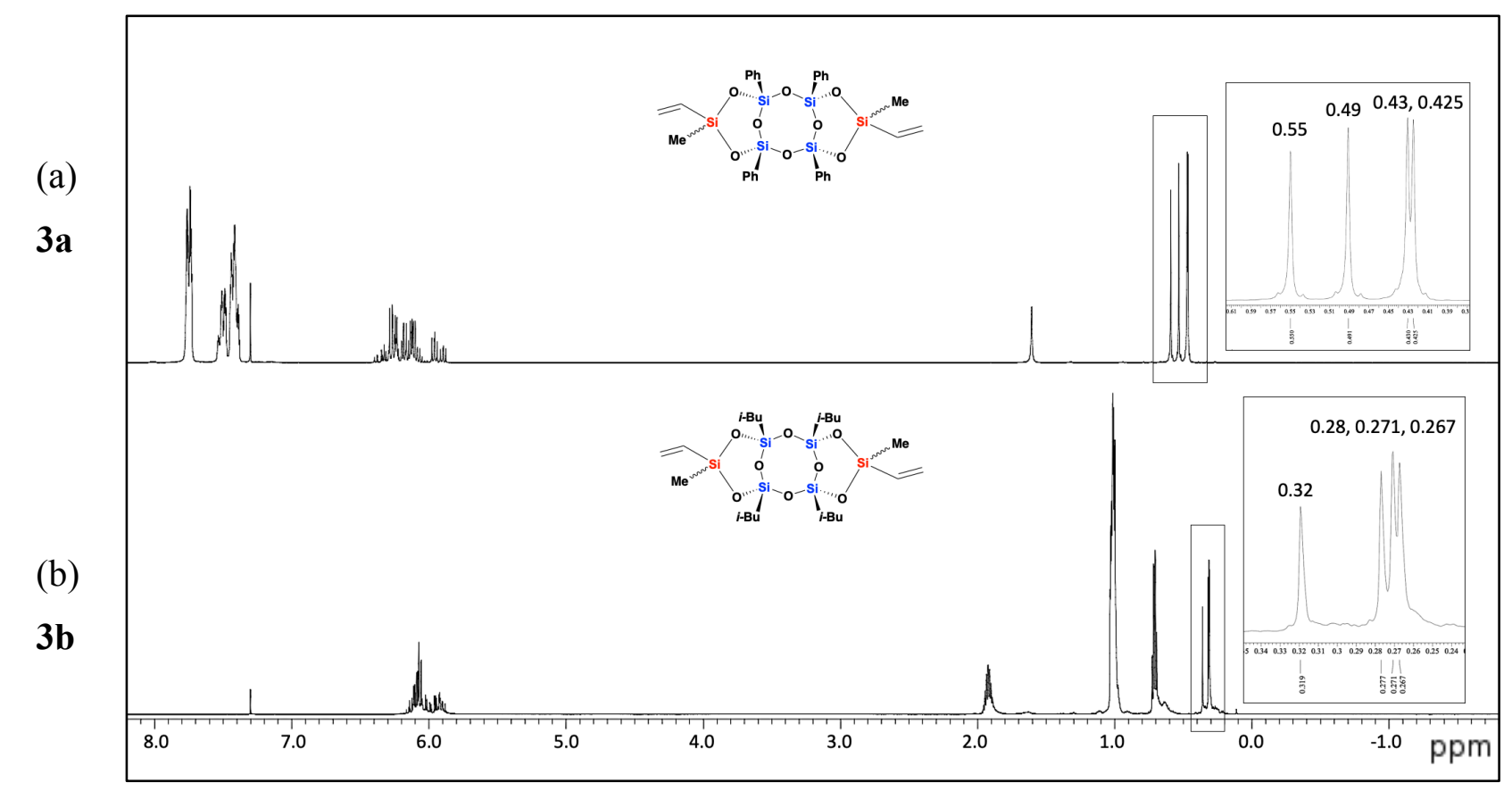

Fig. $1{ }^{1} \mathrm{H}$ NMR spectra (in $\mathrm{CDCl}_{3}$ ) of $\mathbf{3 a}(\mathrm{a})$ and $\mathbf{3 b}(\mathrm{b})$ as a mixture of stereoisomers 


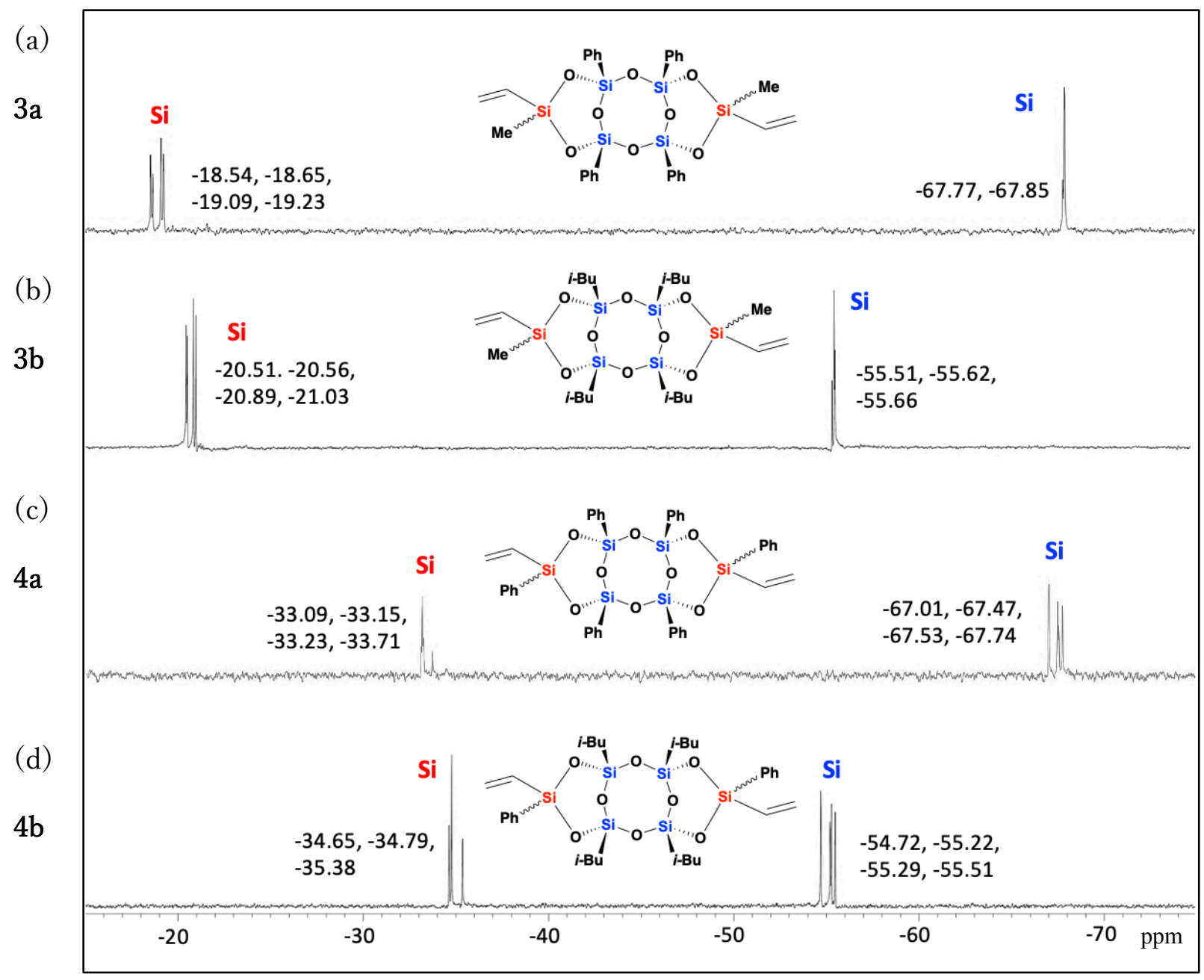

Fig. $2{ }^{29} \mathrm{Si} \mathrm{NMR}$ spectra (in $\mathrm{CDCl}_{3}$ ) of $\mathbf{3 a}(\mathrm{a}), \mathbf{3 b}(\mathrm{b}), \mathbf{4 a}(\mathrm{c})$, and $\mathbf{4 b}(\mathrm{d})$ as mixtures of stereoisomers

The thermal stability of laddersiloxanes $\mathbf{3 a}$ and $\mathbf{3 b}$ was studied by thermogravimetric analysis (TGA) (Table 1, entries 1 and 2). 3a displayed a higher $\mathrm{Td}_{5}\left(293{ }^{\circ} \mathrm{C}\right)$ than $\mathbf{3 b}$ $\left(203{ }^{\circ} \mathrm{C}\right)$ likely due to the presence of phenyl substituents, which brings more thermal robustness as compared to alkyls [32].

To broaden the range of difunctionalized laddersiloxanes, nucleophilic substitution of the previously described tetrasilanolates generated in situ from $\mathbf{1 a}$ and $\mathbf{1 b}$ in the presence of triethylamine was next explored with dichlorophenylvinylsilane $\mathbf{2 b}$ (Scheme 3). 
Corresponding laddersiloxanes 4a and 4b were synthesized in 75 and 85\% yields, respectively, and were next characterized. As in the case of their related methyl-substituted counterparts $\mathbf{3 a}$ and $\mathbf{3 b}$, the formation of stereoisomers occurred as evidenced by the sets of signals observed in the NMR spectra. For example, by ${ }^{29} \mathrm{Si}$ NMR spectroscopy, the magnetically nonequivalent D-group silicon atoms have different resonance frequencies and showed four singlets at $-33.71,-33.23,-33.15$, and -33.09 ppm for $\mathbf{4 a}$ and three at -35.38 , -34.79 and -34.65 ppm for $\mathbf{4 b}$ (two of them being likely overlapped). Equally, T-group silicon atoms produced four peaks at $-67.74,-67.53,-67.47$, and $-67.01 \mathrm{ppm}$ in $\mathbf{4 a}$ and $55.51,-55.29,-55.22$, and $-54.72 \mathrm{ppm}$ in $\mathbf{4 b}$. Elemental analysis and MALDI-TOF mass spectroscopy confirmed the structures (see supporting information).

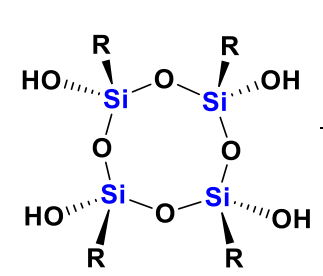

$1 \mathrm{a}(\mathrm{R}=\mathrm{Ph})$ $1 \mathrm{~b}(\mathrm{R}=i-\mathrm{Bu})$<smiles>C=C[Si](Cl)(Cl)c1ccccc1</smiles>

$2 \mathbf{b}$

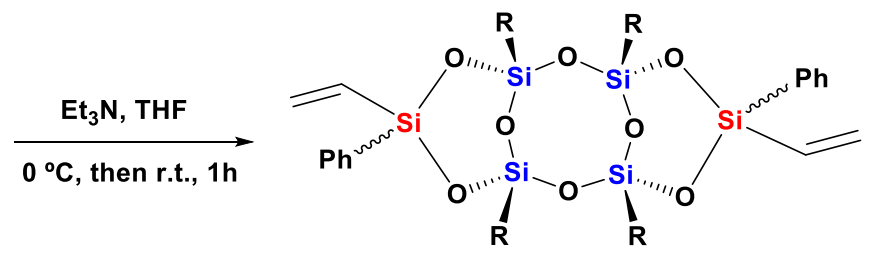

4a $R=P h$, yield: $75 \%$

4b R = i-Bu, yield: $85 \%$

Scheme 3 Synthesis of laddersiloxanes $\mathbf{4 a}$ and $\mathbf{4 b}$

\begin{tabular}{|c|c|c|c|c|c|}
\hline Entry & 1 & 2 & 3 & 4 & 5 \\
\hline Compound & $3 a$ & $\mathbf{3 b}$ & $4 a$ & $4 b$ & 5 \\
\hline $\mathrm{R}^{1}$ & $\mathrm{Ph}$ & $i-\mathrm{Bu}$ & $\mathrm{Ph}$ & $i-\mathrm{Bu}$ & $\mathrm{Ph}$ \\
\hline$\overline{\mathrm{R}^{2}}$ & $\mathrm{Me}$ & $\mathrm{Me}$ & $\mathrm{Ph}$ & $\mathrm{Ph}$ & $\mathrm{Ph}$ \\
\hline $\mathrm{R}^{3}$ & vinyl & vinyl & vinyl & vinyl & $\begin{array}{l}\mathrm{CH}_{2} \mathrm{CH}_{2}- \\
\mathrm{SiMe}_{2} \mathrm{Ph}\end{array}$ \\
\hline $\mathrm{Td}_{5}\left({ }^{\circ} \mathrm{C}\right)$ & 293 & 203 & 343 & 242 & 422 \\
\hline
\end{tabular}

Table 1 TG measurement data of $\mathbf{3 a}, \mathbf{3 b}, \mathbf{4 a}, \mathbf{4 b}$, and $\mathbf{5}$ ' under $\mathrm{N}_{2}$ atmosphere 
The replacement of methyl substituents by phenyls on peripheral silicons increase significantly the thermal stability of $\mathbf{4 a}\left(\mathrm{Td}_{5}=343{ }^{\circ} \mathrm{C}\right)$ compared to $\mathbf{3 a}\left(\mathrm{Td}_{5}=293{ }^{\circ} \mathrm{C}\right.$, Table 1, entries 1 and 3). Along the same lines, the $\operatorname{Td}_{5}$ of $\mathbf{4 b}\left(242{ }^{\circ} \mathrm{C}\right)$ was higher than $\mathbf{3 b}\left(203{ }^{\circ} \mathrm{C}\right.$, Table 1, entries 2 and 4). It is worthy to note that laddersiloxanes $\mathbf{3 a}, \mathbf{3 b}, \mathbf{4 a}$, and $\mathbf{4 b}$ can be easily prepared in gram scale (up to $5 \mathrm{~g}$ per reaction) and the syntheses can certainly still be scaled up. As expected, laddersiloxane 4a bearing phenyl groups both on the $\mathrm{T}_{4}$-unit and on the peripheral silicon atoms displayed the best thermal stability and appeared as a most promising candidate for further incorporation in hybrid materials.

As a proof of concept, the functionalization of $\mathbf{4 a}$ through hydrosilylation was achieved (Scheme 4). In the presence of dimethylphenylsilane and a very small amount of Karstedt catalyst $(0.02 \mathrm{~mol} \%$ Pt per $\mathrm{C}=\mathrm{C}), \mathbf{4 a}$ quantitatively yielded laddersiloxane 5 as a mixture of three stereoisomers as expected and shown by the resonance patterns of the ${ }^{1} \mathrm{H},{ }^{13} \mathrm{C}$ and ${ }^{29} \mathrm{Si}$ NMR spectra (see supporting information).
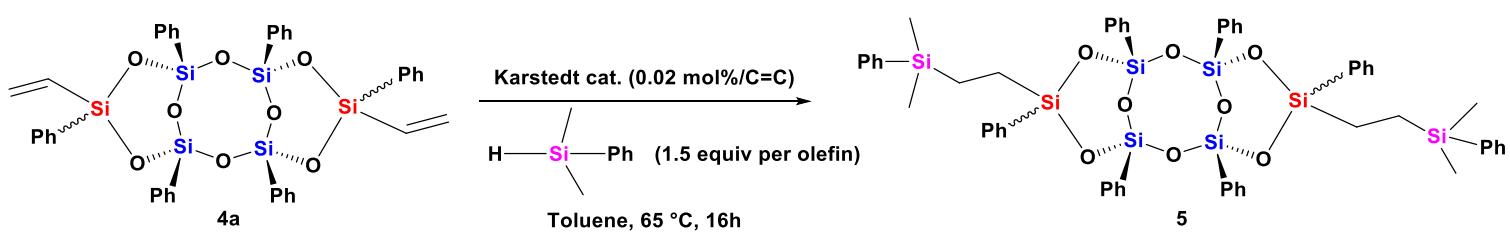

Scheme 4 Synthesis of laddersiloxane 5

To our delight, after washing the mixture with cold hexane, one of the stereoisomers of 5 could be isolated from the filtrate as a white solid 5' in 19\% yield. The latter was characterized by multinuclear NMRs, mass spectroscopy and elemental analysis. On the ${ }^{29} \mathrm{Si}$ NMR spectrum of the isolated stereoisomer (Figure 3), the silicon atoms from the $\mathrm{T}_{4}$-unit (blue $\mathrm{Si}$ ) resonated as a singlet at $-66.63 \mathrm{ppm}$, while the D-group silicon atoms (red $\mathrm{Si}$ ) gave rise to a singlet $-18.89 \mathrm{ppm}$. The third singlet at $-0.58 \mathrm{ppm}$ was assigned to those of carbosilanes (pink Si). This stereoisomer displaying high symmetry could correspond to isomers (I) or (III) (Scheme 2). 

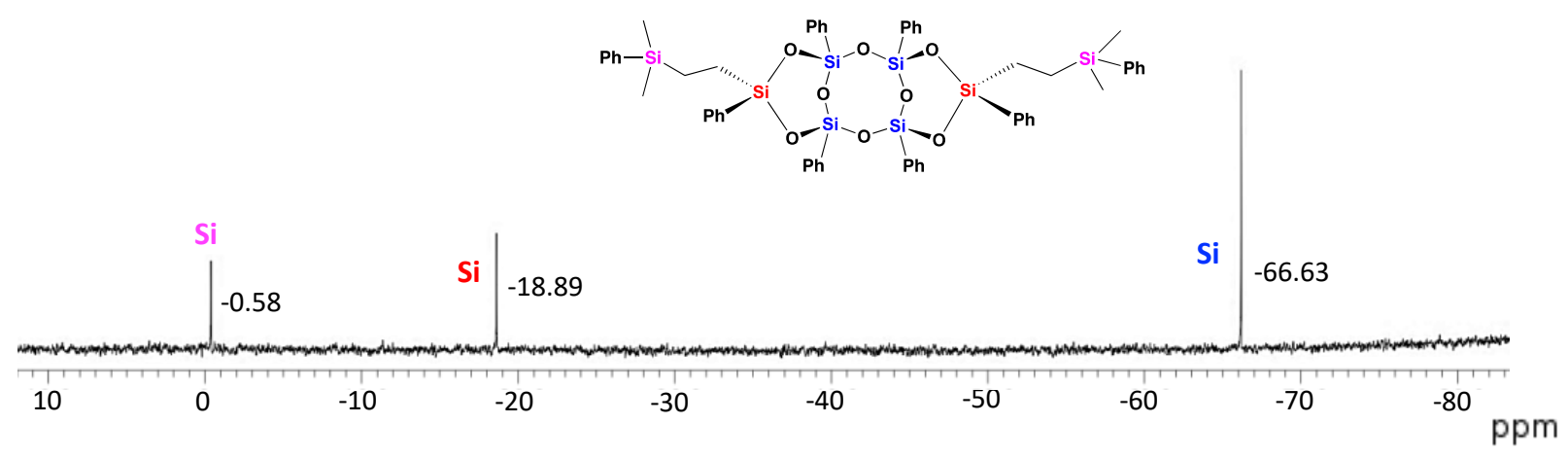

Fig. $3{ }^{29} \mathrm{Si} \mathrm{NMR} \mathrm{spectrum} \mathrm{(in} \mathrm{CDCl}_{3}$ ) of 5' (isolated isomer of (I)- or (III), see Scheme 2)

MALDI-TOF confirms the structure with the experimental mass $\left(1108.84[\mathrm{M}+\mathrm{Na}]^{+}\right.$and $\left.1124.82[\mathrm{M}+\mathrm{K}]^{+}\right)$, in good accord with the calculated ones $\left(1108.76[\mathrm{M}+\mathrm{Na}]^{+}\right.$and 1124.87 $[\mathrm{M}+\mathrm{K}]^{+}$, Figure 4). Elemental analysis also attests to the purity of isolated laddersiloxane (see supporting information). Compound $\mathbf{5}$ ' was further recrystallized from chloroform and hexane by slow evaporation to give single crystals suitable for X-ray analysis (Figure 5, Table 2). As expected, 5' displayed a syn-type structure and was found to correspond to the stereoisomer (I) (Scheme 2). Interestingly, 5' was shown to be highly thermally stable with a measured $\mathrm{Td}_{5}$ at $422{ }^{\circ} \mathrm{C}$.

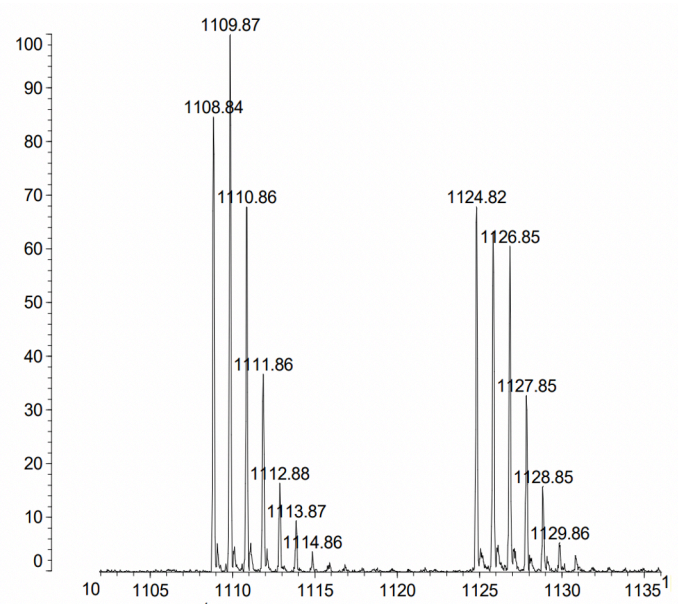

Fig. 4 MALDI-TOF mass spectrum of laddersiloxane 5', 


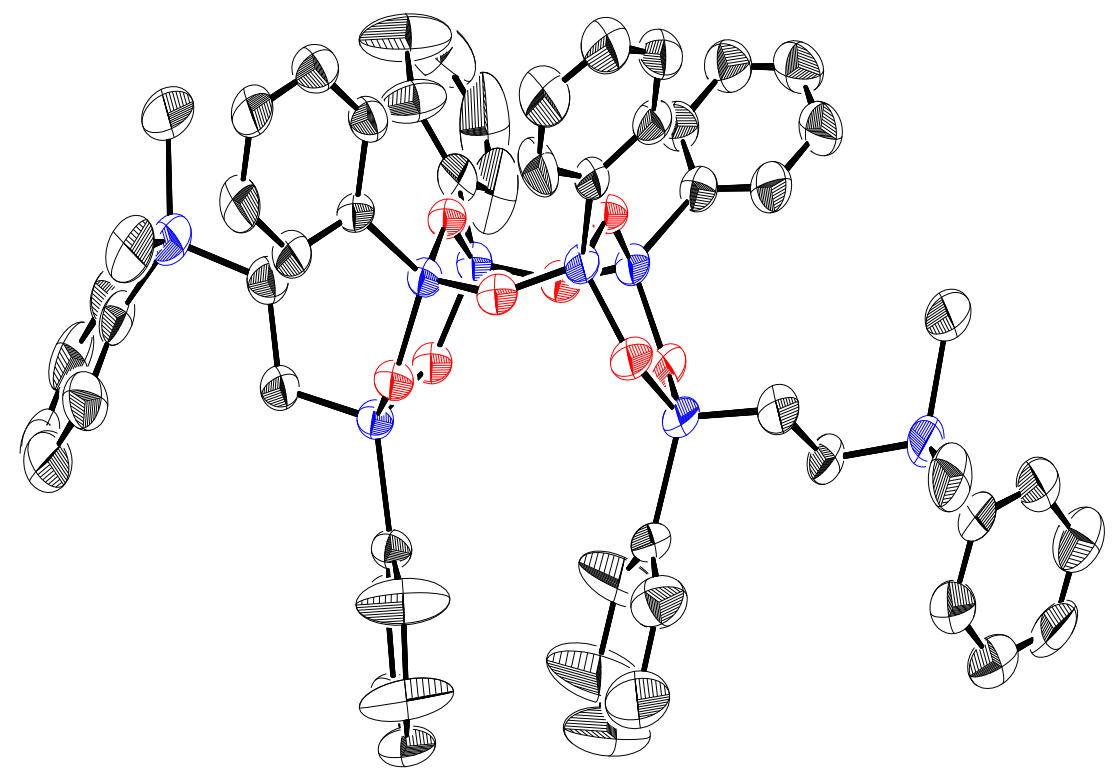

Fig. 5 X-ray structure of laddersiloxane 5'. Black: carbon; blue: silicon; red: oxygen

\begin{tabular}{|l|l|}
\hline Compounds & $\mathbf{5}^{\prime}$ \\
\hline empirical formula & $\mathrm{C}_{56} \mathrm{H}_{60} \mathrm{O}_{8} \mathrm{Si}_{8}$ \\
\hline formula weight & 1085.76 \\
\hline temperature $(\mathrm{K})$ & 130 \\
\hline crystal system & Orthohombic \\
\hline space group & $\mathrm{P} 22_{1} 2_{1}$ \\
\hline$a(\AA)$ & $10.7393(17)$ \\
\hline$b(\AA)$ & $18.409(3)$ \\
\hline$c(\AA)$ & $29.205(5)$ \\
\hline$\alpha(\operatorname{deg})$ & 90 \\
\hline$\beta(\operatorname{deg})$ & 90 \\
\hline$\gamma(\operatorname{deg})$ & 90 \\
\hline
\end{tabular}

Table 2 Crystal Data for compound 5'

\section{Conclusions}

To conclude, an efficient synthetic route to difunctionalizable laddersiloxanes is described. Four laddersiloxanes bearing various alkyl or phenyl groups and two peripheral vinyl reactive substituents were synthesized in high yields (from 73 to $93 \%$ ) and in the gram scale (up to 5 g). The mixture of formed stereoisomers was characterized by multinuclear NMRs and mass spectroscopy and the thermal stability was estimated by thermogravimetric analysis. The 
most stable laddersiloxane $4 \mathbf{a}\left(\mathrm{Td}_{5}=343^{\circ} \mathrm{C}\right)$ was quantitatively functionalized through a model hydrosilylation with dimethylphenylsilane. One stereoisomer (5') was successfully isolated out of the resulting laddersiloxane (5) obtained as a mixture of three stereoisomers and was fully characterized (multinuclear NMRs, MALDI-TOF, elemental analysis). Thanks to the structural determination by X-ray crystallography, the relative positions of the different substituents on the stereoisomer 5' were determined. In addition, this compound is highly stable $\left(\mathbf{5}^{\prime}, \mathrm{Td}_{5}=422{ }^{\circ} \mathrm{C}\right)$. Laddersiloxane $4 \mathbf{a}$ thus represents a promising building block that will be easily incorporated in various hybrid materials thanks to its relatively high thermal stability and high reactivity of its peripheral vinyl groups. The resulting materials could include the assets of highly-ordered ladder-shaped rigid inorganic siloxane rings such as high thermal and mechanical stabilities, high transparency, flexibility and good solubility. Applications of these functionalizable laddersiloxanes are currently underway in our laboratories.

\section{Declarations}

\section{Funding statement}

Partial financial support was received from the New Energy and Industrial Technology Development Organization (NEDO) under Grant named "Development of Innovative Catalytic Processes for Organosilicon Functional Materials" project (PL: K. Sato).

\section{Conflict of Interest}

The authors declare no financial or commercial conflict of interest.

\section{Availability of data and material}

All data and material described in this article can be available.

\section{Author contributions}

Conceptualization: Armelle Ouali, Masafumi Unno; Methodology: Armelle Ouali, Yujia Liu, Formal analysis and investigation: Yujia Liu, Aimi Endo, Peiyao Zhang, Akira Takizawa, Nobuhiro Takeda; Writing - original draft preparation: Armelle Ouali, Yujia Liu; Writing review and editing: Armelle Ouali, Masafumi Unno, Funding acquisition: Masafumi Unno, Armelle Ouali

\section{Consent to participate}

All authors agreed to participate in this publication. 


\section{Consent for Publication}

All authors agreed to the publication of this article.

\section{Conflict of Interest}

The authors declare no financial or commercial conflict of interest.

\section{References}

1. Cordes DB, Lickiss PD, Rataboul F (2010) Recent Developments in the Chemistry of Cubic Polyhedral Oligosilsesquioxanes. Chem Rev 110: 2081-2173

2. Laine RM, Roll MF (2011) Polyhedral Phenylsilsesquioxanes. Macromolecules 44: 1073-1109

3. Ye Q, Zhou H, Xu J (2016) Cubic Polyhedral Oligomeric Silsesquioxane Based Functional Materials: Synthesis, Assembly, and Applications. Chem Asian J 11: 13221337

4. Zhou H, Ye Q, Xu J (2017) Polyhedral oligomeric silsesquioxane-based hybrid materials and their applications. Mater Chem Front 1:212-230

5. Du Y, Liu H (2020) Cage-like silsesquioxanes-based hybrid materials. Dalton Trans 49:5396-5405.

6. Calabrese C, Aprile C, Gruttadauria M, Giacalone F (2020) POSS nanostructures in catalysis. Catal Sci Technol 10:7415-7447

7. Dudziec B, Zak P, Marciniec B (2019) Synthetic Routes to Silsesquioxane-Based Systems as Photoactive Materials and Their Precursors. Polymers 11:504

8. Chen F, Lin F, Zhang Q, Cai R, Wu Y, Ma X (2019) Polyhedral Oligomeric Silsesquioxane Hybrid Polymers : Well-Defined Architectural Design and Potential Functional Applications. Macromol Rapid Commun 40:1900101

9. Wang J, Du W, Zhang Z, Gao W, Li Z (2021) Biomass/polyhedral oligomeric silsesquioxane nanocomposites : Advances in preparation strategies and performances. J Appl Polym Sci 138:e49641

10. Mohamed MG, Kuo SW (2019) Functional Polyimide/Polyhedral Oligomeric Silsesquioxane Nanocomposites. Polymers 11:26

11. Li Z, Hu J, Yang L, Zhang X, Liu X, Wang Z, Li Y (2020) Integrated POSS-Dendrimer Nanohybrid Materials: Current Status and Future Perspective. Nanoscale 12:1139511415

12. Chi H, Wang M, Xiao Y, Wang F, Joshy KS (2018) Self-Assembly and Applications of Amphiphilic Hybrid POSS Copolymers. Molecules 23:2481

13. Dudziec B, Marciniec B (2017) Double-decker Silsesquioxanes: Current Chemistry and Applications. Curr Org Chem 21:2794-2813

14. Wang M, Chi H, Joshy KS, Wang F (2019) Progress in the Synthesis of Bifunctionalized Polyhedral Oligomeric Silsesquioxane. Polymers 11:2098

15. Kamino BA, Bender TP (2013) The use of siloxanes, silsesquioxanes, and silicones in organic semiconducting materials. Chem Soc Rev 42:5119-5130 
16. Lee A, Jo YY, Choi S, Baek K, Hwang S (2017) Thermal, Mechanical, and Photophysical Properties of Carbazole-Substituted POSS and Ladder Polysiloxane. J Nanosci Nanotechnol 17:5562-5565

17. Kang W, An G, Kim MJ, Lee WH, Lee DY, Kim H, Cho JH (2016) Ladder-Type Silsesquioxane Copolymer Gate Dielectrics for High-Performance Organic Transistors and Inverters. J Phys Chem C 120:3501-3508

18. Kim MJ, Heo YM, Cho JH (2017) Ladder-type silsesquioxane copolymer gate dielectrics for gating solution-processed IGZO field-effect transistors. Org Electron 43:41-46

19. Unno M, Suto A, Matsumoto H (2002) Pentacyclic Laddersiloxane. J Am Chem Soc 124:1574-1575

20. Unno M, Tanaka R, Tanaka S, Takeuchi T, Kyushin S, Matsumoto H (2005) Oligocyclic Ladder Polysiloxanes: Alternative Synthesis by Oxidation. Organometallics 24:765-768

21. Unno M, Matsumoto T, Matsumoto H (2007) Synthesis of laddersiloxanes by novel stereocontrolled approach. J Organomet Chem 692:307-312

22. Seki H, Abe N, Abe Y, Gunji T (2011) Synthesis and Structure of syn,anti,synPentacyclic Ladder Oligomethylsilsesquioxane. Chem Lett 40:722-723

23. Chang S, Matsumoto T, Matsumoto H, Unno M (2010) Synthesis and characterization of heptacyclic laddersiloxanes and ladder polysilsesquioxane. Appl Organometal Chem 24:241-246

24. Unno M, Matsumoto T, Matsumoto H (2012) Nonacyclic Ladder Silsesquioxanes and Spectral Features of Ladder Polysilsesquioxanes. Int J Polym Sci 2012:723892

25. Unno M, Suto A, Matsumoto T (2013) Laddersiloxanes - silsesquioxanes with defined ladder structure. Russ Chem Rev 82:289-302

26. Endo H, Takeda N, Takanashi M, Imai T, Unno M (2015) Refractive Indices of Silsesquioxanes with Various Structures. Silicon 7:127-132

27. Du Y, Unno M, Liu H (2020) Hybrid Nanoporous Materials Derived from Ladder- and Cage-Type Silsesquioxanes for Water Treatment. ACS Appl Nano Mater 3:1535-1541

28. Liu Y, Onodera K, Takeda N, Ouali A, Unno M (2019) Synthesis and Characterization of Functionalizable Silsesquioxanes with ladder-type Structures. Organometallics 38:4373-4376

29. Liu Y, Kigure M, Okawa R, Takeda N, Unno M, Ouali A (2021) Synthesis and Characterization of Tetrathiol-substituted Double-Decker or Ladder Silsesquioxane Nano-Cores. Dalton Trans Accepted Manuscript DOI: 10.1039/D1DT00042J

30. Ito R, Kakihana Y, Kawakami Y (2009) Cyclic Tetrasiloxanetetraols: Formation, Isolation, and Characterization. Chem Lett 38:364-365

31. Endo H, Takeda N, Unno M (2017) Stereoisomerization of Cyclic Silanol. Chem Asian J 12:1224-1233

32. Endo H, Takeda N, Unno M (2014) Synthesis and Properties of Phenylsilsesquioxanes with Ladder and Double-Decker Structures. Organometallics 33:4148-4151 